\title{
Design and Development of a Web Based Dynamic Assessment System to Increase Students' Learning Effectiveness
}

\author{
Arif Tuluk (D) 1, , Halil Yurdugul (iD)2 \\ ${ }^{1}$ Ministry of National Defense, 06550, Ankara, Turkey \\ 2 Hacettepe University, Faculty of Education, Computer Education \& Instructional Technology Department, \\ 06800, Ankara, Turkey
}

ARTICLE HISTORY

Received: May 01, 2020

Revised: Sep. 07, 2020

Accepted: Oct. 15, 2020

\section{KEYWORDS}

Web-based assessment, Formative assessment, Dynamic assessment, Web-based dynamic assessment

\begin{abstract}
As Bloom (1984) stated that the way to increase students' achievements with one-to-one tutorial support can be the subject of instructional technologies today. In this context, the aim of the study was to design, develop and improve a web-based dynamic assessment system aimed at contributing to mathematics learning of secondary school students. For this purpose, a teaching environment has been designed in which $5^{\text {th }}$ grade students can test themselves independently of time and place through internet technologies to learn mathematics lesson topics. A web-based environment combining the principles of dynamic assessment and gamification has been developed with the dynamic assessment algorithm developed within the scope of the research. The research is structured in accordance with the "Type 1" study features, one of the developmental research types. During the development of the prototype, pilot implementation was carried out with $475^{\text {th }}$ grade students. In addition, focus group discussions were held with 12 students using the system. According to the findings obtained, it was concluded that the secondary school students' success scores constantly increase in each achievement, the instructional guidance they receive in each test decreases continuously and they can perform the next assessment tasks without help. The students stated that they were directed to the correct solution by the system while solving the questions they did not know, the instructional guidances for the solution were very helpful, the visual elements (monkey, robot and banana) were interesting, fun and beautiful and they wanted to use this system in other lessons.
\end{abstract}

\section{INTRODUCTION}

One of the main objectives of instructional technologies is to develop technological applications to facilitate and / or increase learning. As a result of his extensive research, Bloom (1984) emphasized that the basic conditions of increasing the learning on a subject by two standard deviations from the average are a) mastery learning model and together with b) one-to-one tutoring. Students need support in their learning processes, in other words, intervention. Especially considering that there is no teacher in new generation learning environments, digital systems should provide this support. The concept of support mentioned here has two different dimensions, respectively, the support in the learning process and the other is the support during problem solving. Supporting students in the problem solving phase is modeled with intelligent 
tutoring systems (ITS). However, the point to be emphasized here is that ITS and structured learning systems (e-learning systems) are different concepts. To explain this difference, the students' learning systems at school (learning systems) and at institutions such as classrooms and courses (tutoring systems) can be given as examples. While learning systems (such as learning management systems) offer enriched learning environments for the purposes of the course and based on the instructional design, the main purpose in ITS is to support students in the problem solving process. In this context, the support offered to students in problem solving situations can be provided through a dynamic assessment system.

As Bloom (1984) stated that the way to increase students' achievements with one-to-one tutorial support can be the subject of education technologies today. In this context, web-based dynamic assessment systems that can provide instructional support to learners can be made thanks to instructional technologies. It is seen in the literature that many technology supported environment designs have been developed in order to support students (Ashton, et al. 2006; Costa, Kothe, Mullan \& Butow, 2010; Critchley, Ware, Kumta \& Wong, 2009; Marinagi, 2011; Wang, 2007, 2010, 2011, 2014; Wang, Wang, Wang \& Huang, 2006; Zou \& Zhang, 2013). When the studies conducted to increase student success are examined, there are differences in the designs of these studies; some studies have included gamified dynamic assessment items (eg, a false option is reduced, I want to ask my friend option, leader board, etc.), while others (for example, algorithms based on the assessment task and the scaffolding relationship) have been differences in the algorithms used. It can be argued that it is important to examine the algorithms in gamification elements and assessment task-guiding relations. In the studies analyzed in this context, no study with web-based dynamic assessment has been encountered in our country. It can be suggested that an e- assessment system, which supports the out-ofschool learning experiences in addition to the in-school learning experiences of the students at the target audience level (secondary school level), includes different instructional guidances according to different types of knowledge. In addition to the rapid increase in the use of webbased technologies for learner-oriented assessments in higher education, the use of such assessment systems, especially in classroom environments at the K-12 level, is new. Within the scope of the research, it is thought that the literature will contribute to secondary school students in terms of providing them with the opportunity to monitor their own learning and development instantly by using the web based dynamic assessment system. In addition, it is thought that it will contribute to the literature in terms of the design model proposed by the research according to its educational purpose. Other issues that the research is thought to contribute to the literature are as follows:

- The research is a study carried out in terms of making a significant contribution to the achievement of the educational objectives of the students at the secondary school level by the web-based dynamic assessment system.

- In web-based assessment systems, there are serious problems in keeping the learners in the system and ensuring their continuity, and these results in the learners leaving the system. In this research, there are gamification elements to keep the learners in the system and ensure their continuity in each acquisition test process. With this aspect, it is a study carried out in order to ensure the permanence and continuity of the learners by embedding gamification elements into the system.

- The research is a study in which $5^{\text {th }}$ grade students at K-12 level at K-12 at the level of web-based dynamic assessment can take instructional guides as instructors in the process and improve themselves continuously.

The research is a study that shows whether $5^{\text {th }}$ grade students at secondary school level have an effective learning experience, whether there are assessment items that are incorrectly answered as a result of carelessness, if there are lesson topics that are deficient, and that they can eliminate 
the missing subjects through instructive measures and show their educational development levels.

\section{Research Questions}

Within the scope of the research, assessment environments and processes have been designed with the dynamic assessment system based on web-based teaching developed. With this environment, it has been tried to contribute to the learning and teaching process with the processes developed to identify and eliminate the deficiencies in learning mathematics. In this research, it is aimed to examine how to design a web-based dynamic assessment system for students at secondary school level to learn mathematics. For this purpose, the following questions were sought in this research;

1. For the design process of a web-based dynamic assessment system,

a. What is needed to develop a web based dynamic assessment system according to the literature?

b. What should be the features and functions of a web-based dynamic assessment system?

c. What are the issues that need to be developed in the web-based dynamic assessment system?

d. What are the design changes based on the assessment of the developed system?

2. What are the students' views on the web-based dynamic assessment system?

\section{REVIEW OF THE LITERATURE}

This topic covers the concept of dynamic assessment and the design of the web-based dynamic assessment system.

\subsection{Dynamic Assessment}

The focus of formative assessment is very different from summative assessment. According to Haywood, Brown and Wingenfeld (1990), summative assessment is used to assess performance at a given moment and there is no attempt to change this performance. Formative assessment aims at revealing students' learning deficits and difficulties leading to these deficiencies. Dynamic assessment is a type of formative assessment, a general and inclusive concept that is used to explain different types of approaches, involves teaching, is presented in the assessment process of feedback and differs on the basis of individual performances (varying according to the individual's performance). One of the main objectives of dynamic assessment is to improve the performance of learners by providing instructional aids with assessment tasks.

The development of dynamic assessment has been heavily influenced by L.S. Vygotsky (Allal \& Ducrey, 2000; Haywood, et al., 1990). Vygotsky (1978) stated that, with the help of an adult, the performance level of children can be improved. Vygotsky proposed the theory of "The zone of proximal development (ZPD)" to describe the difference between children's performance without the help of adults and more competent peers. ZPD represents children's learning potential. By interacting with adults or more competent peers, children's learning potential can be revealed and learning activities can also be improved. By interacting with the dynamic assessment system, the learners try to improve their learning performance with the help of tutorials in the assessment tasks presented to them. In this context, it is thought that learners will contribute to the ZPD by developing their learning potential with the dynamic assessment system.

Dynamic assessment is an interactive assessment commonly given as "test-teach-retest" (Haywood \& Lidz, 2007; Moore-Brown et al., 2006). It has been revealed that the researchers who examined the formats of dynamic assessment and related research findings had various 
opinions on how to effectively manage dynamic assessment (Elliott, 2003; Sternberg \& Grigorenko, 2001). Two basic instructional features were shared on this subject:

- Individuals are given the opportunity to learn (Bransford, et al., 1987).

- Teaching and feedback are included in the testing process (Elliott, 2003).

In this context, it is possible to divide the dynamic assessment into two as interactionist and interventionist dynamic assessment. In interactionist dynamic assessment, measurement is avoided and qualitative assessment of a person's learning potential is concerned. It aims to provide the failed individual with a necessary understanding of the assessment items and possible ways of resolving these assessment items. Then, after the individual has developed the ability to solve this task (through mediation work with the teacher or trainer), their ability to overcome similar tasks is evaluated. Interventionist dynamic assessment includes measurable pre-programmed help and is directed to measurable psychometric measurement. In other words, aid takes the form of standardized interventions developed to measure the capacity of individuals or groups to use predetermined guidance, feedback and support to "increase predictive validity of the assessment process".

According to Sternberg and Grigorenko (2001), dynamic assessment has two forms: sandwich form and cake form. Both formats are implemented as "test-teach-retest". Sandwich formatted dynamic assessment means that teaching is held between pre-test and post-test, thus creating a sandwich-like process. Teaching in cake-type dynamic assessment is a response to the researchers' answers to each question. The main difference between sandwich form dynamic assessment and cake form dynamic assessment is that education and assessment are separate from dynamic assessment in sandwich format but are combined with dynamic assessment in cake form.

\subsection{Web Based Dynamic Assessment System}

The web-based dynamic assessment system adopted in this research was designed as a cake form interventionist dynamic assessment. The web-based dynamic assessment system is a learner-oriented system, and it is expected that students can determine whether they have performed effective learning, whether there are questions that they answer incorrectly as a result of carelessness, whether there are issues missing, to contribute to achieving their educational goals, and to improve learning strategies and to organize learning processes.

The main feature of dynamic assessment in the form of cakes is the design of consecutive clues with a series of progressive clues. With the designed system, students are provided with gradual instructional guidance (IG) regarding their problems regarding assessment tasks. In this design, reference is made to the "graduated prompt approach" proposed by Campione and Brown $(1985,1987)$ and the mathematical problem solving theory of Mayer (1992). According to Campione and Brown, hints in the phased graduated approach are presented in a predetermined order, arranged according to the level of disclosure (Bransford, et al., 1987). They begin with "general tips" and gradually become "specific tips". General hints offer relatively little specific information about the solution, while a specific hint provides a detailed instruction in which students can produce the correct answer (Campione \& Brown, 1985, 1987). Mayer argued that solving mathematical problems involves two sub-processes, namely "problem representation" and "problem solving", and "translation", "integration", "planning and monitoring" and "execution". Three IGs (IG1, IG2, IG3) are designed to compensate students for missing information at each stage and sub-process. With these IGs, the necessary mathematical problem solving knowledge is expected to compensate for the lack of learners, but also improve their learning. In this research, the "graduated prompt approach" and the tips provided by the dynamic assessment elements were used as a reference to develop the web-based dynamic assessment system. These clues are called instructional guidance (IG), as they are used to guide 
and teach students. When students answer an item incorrectly, they gradually receive IGs and learn to find the right answer step by step.

\section{METHOD}

This part covers the research model, the participants of the research, the design and development of the web-based dynamic assessment system, data collection process, data collection tools and data analysis.

\subsection{Research Model}

In this research, the design, development and improvement processes of the web based dynamic assessment system are planned as "developmental research". Developmental research are considered as two types; Design, development and assessment of a particular product (Type 1), focusing on specific design, development and assessment processes, tools or models (Type 2) (Richey, Klein \& Nelson, 2004). While the researcher has the role of both researcher and designer in a special development context in Type 1, the researcher has the role of implementing only one tool / model in Type 2 (Van den Akker, 1999). This research is structured in accordance with the characteristics of "Type 1" study, one of the developmental research types. Working process in the design, development and improvement of the web-based dynamic assessment system; starting with the analysis of the problem, the development of systemic solutions (prototype creation-design), testing of solutions (use of prototype-research) and improvement processes were carried out. Summary information about the stages followed in this research, the operations performed at these stages, data sources and output are presented in Table 1.

Table 1. Stages of the Research, Processes, Data Sources and Outputs

\begin{tabular}{|c|c|c|c|}
\hline Stages of the Research & Operations & Data Sources & Output \\
\hline Requirement Analysis & $\begin{array}{l}\text { Examining the related } \\
\text { literature (systematic } \\
\text { content analysis) }\end{array}$ & $\begin{array}{l}\text { Literature (98 } \\
\text { articles) }\end{array}$ & Requirement list \\
\hline $\begin{array}{l}\text { Design } \\
\text { (Creating the Prototype) }\end{array}$ & $\begin{array}{l}\text { - Creating a prototype in } \\
\text { accordance with the } \\
\text { elements and components } \\
\text { planned to be included in } \\
\text { the system design. } \\
\text { - Prototype testing and } \\
\text { revision }\end{array}$ & Expert opinions & $\begin{array}{l}\text { - System components } \\
\text { - System elements and } \\
\text { features } \\
\text { - System prototype }\end{array}$ \\
\hline $\begin{array}{l}\text { Development } \\
\text { (Using the Prototype) }\end{array}$ & $\begin{array}{l}\text { - Pilot implementation of } \\
\text { the prepared prototype } \\
\text { - Focus group meeting }\end{array}$ & Target group & $\begin{array}{l}\text { Learning environment } \\
\text { (final product) }\end{array}$ \\
\hline Improvement & $\begin{array}{l}\text { - Focus group meeting } \\
\text { - Making design changes } \\
\text { based on assessment }\end{array}$ & Target group & $\begin{array}{l}\text { Learning environment } \\
\text { (improved product) }\end{array}$ \\
\hline
\end{tabular}

As seen in Table 1, the research was carried out in a formative manner in four basic stages. The research process started with literature review, referring to what was done at each stage of this research and the syllabus given in Table 1, and finalized the process of designing, developing and improving the web-based dynamic assessment system. The research was completed within eight months. 


\subsection{Participants}

This research was carried out together with field experts and $5^{\text {th }}$ grade students in accordance with the design principles. During the design, development and improvement of the web-based dynamic assessment system prototype, semi-structured interviews were made with working groups continuously. In this research, the information about the period when the data was collected, the people with which the data were collected, their frequencies, data sources, data collection tools and research problem numbers are presented in Table 2.

Table 2. Information on the Data Collection Process

\begin{tabular}{|c|c|c|c|c|c|c|}
\hline Process Name & Time & Participants & Frequency & $\begin{array}{l}\text { Data } \\
\text { Sources }\end{array}$ & $\begin{array}{l}\text { Data } \\
\text { Collection } \\
\text { Tools }\end{array}$ & $\begin{array}{l}\text { Research } \\
\text { Problem } \\
\text { No }\end{array}$ \\
\hline $\begin{array}{l}\text { Requirement } \\
\text { Analysis }\end{array}$ & $2017-2019$ & $\begin{array}{l}\text { Related } \\
\text { Studies }\end{array}$ & 98 & Literature & $\begin{array}{l}\text { Systematic } \\
\text { descriptive } \\
\text { scanning }\end{array}$ & $\begin{array}{c}\text { Sub- } \\
\text { Problem } \\
\text { No:1a }\end{array}$ \\
\hline $\begin{array}{l}\text { Design } \\
\text { (Creating the } \\
\text { Prototype) }\end{array}$ & $\begin{array}{l}2017-2018 \\
\text { academic year } \\
\text { fall and spring } \\
\text { semester }\end{array}$ & $\begin{array}{l}\text { Field } \\
\text { experts }\end{array}$ & 7 & $\begin{array}{c}\text { Expert } \\
\text { opinions }\end{array}$ & $\begin{array}{l}\text { Getting } \\
\text { expert } \\
\text { opinions }\end{array}$ & $\begin{array}{l}\text { Sub- } \\
\text { Problem } \\
\text { No.:1b }\end{array}$ \\
\hline $\begin{array}{l}\text { Development } \\
\text { (Using the } \\
\text { Prototype) }\end{array}$ & $\begin{array}{l}2017-2018 \\
\text { academic year } \\
\text { spring } \\
\text { semester }\end{array}$ & $\begin{array}{l}\text { Secondary } \\
\text { school } 5^{\text {th }} \\
\text { grade } \\
\text { students }\end{array}$ & 47 & $\begin{array}{l}\text { Secondary } \\
\text { school } \\
\text { students }\end{array}$ & $\begin{array}{l}\text { Use of the } \\
\text { system by } \\
\text { students } \\
\text { and focus } \\
\text { group } \\
\text { discussions }\end{array}$ & $\begin{array}{l}\text { Sub- } \\
\text { Problem } \\
\text { No.:1c }\end{array}$ \\
\hline Improvement & $\begin{array}{l}2018-2019 \\
\text { academic year } \\
\text { fall semester }\end{array}$ & $\begin{array}{l}\text { Secondary } \\
\text { school } 5^{\text {th }} \\
\text { grade } \\
\text { students }\end{array}$ & 12 & $\begin{array}{l}\text { Secondary } \\
\text { school } \\
\text { students }\end{array}$ & $\begin{array}{l}\text { Focus } \\
\text { group } \\
\text { discussions }\end{array}$ & $\begin{array}{l}\text { Sub- } \\
\text { Problem } \\
\text { No.:2 }\end{array}$ \\
\hline
\end{tabular}

Within the scope of the requirement analysis for the design and development of the web-based dynamic assessment system, the studies conducted on the dynamic assessment and static assessment systems developed for e-learning and personalized learning environments in the literature were analyzed by systematic review. In the process of establishing the web-based dynamic assessment system prototype, the opinions of 3 experts from the field of computer and instructional technologies, 2 as subject matter experts for the course contents in mathematics lesson and 2 from the field of measurement and assessment were consulted. In the process of using the prototype, the web-based dynamic assessment system has been presented as a pilot application to $475^{\text {th }}$ grade students in a public school in a province of İzmir under the Ministry of National Education. In the process of improving the web-based dynamic assessment system, the system was introduced to $125^{\text {th }}$ grade students in a public secondary school and focus group discussions were held with these students. For the students who participated in the research, the students were allowed to participate on a voluntary basis by obtaining permission from the ethics committee commission.

\subsection{Design and Development of Web-Based Dynamic Assessment System}

In this section, the steps taken during the design and development of the web-based dynamic assessment system are described. The purpose of this process is to develop effective software by using resources efficiently. For this purpose, the Rapid Prototyping Model of Tripp and Bichelmeyer (1990) was taken as reference within the scope of its fitness for purpose in the design of the education system for the design and development of the system. In this model, 
first a prototype was produced, then this prototype was tested, necessary corrections were made in accordance with the available data, and the system was completed when it reached to the point without error. There are four main processes in the Reference Rapid Prototyping Model. These processes,

- requirement analysis,

- creating the prototype (design),

- using the prototype (development),

- improving of the system.

\subsubsection{Stage 1: Requirement analysis}

Within the scope of the requirement analysis for the design and development of the web-based dynamic assessment system, studies on the dynamic assessment and static assessment systems developed for e-learning and personalized learning environments have been examined. In order to access related studies, first of all, keywords that are suitable for the purpose of the research and the problem sentence have been determined. Keywords were determined as web-based assessment, formative assessment, dynamic assessment. The determined keywords were scanned by creating different search queries in academic databases (ERIC, JSTOR, Science Direct, Scopus, Springer, Taylor \& Francis, Web of Science). By using search queries, related studies have been reached by searching through relevant international academic databases, printed and electronic journals and books, Google Scholar and various academic social networks (Academia, ResearchGate). As a result of the examination of the studies in the literature, the need to design and develop a web-based dynamic assessment system has emerged. In this context, it was decided to support this research with algorithms based on the interventionist dynamic assessment process by examining the interventionist and interactive dynamic assessment approaches and considering the research problem. Accordingly, the learner-instructional guidance interaction algorithm has been developed (Figure 1).

As indicated in Figure 2, in cake-form interventionist dynamic assessment, the assessment is always carried out in an individualized way. The learners who are subject to the test receive instructions by answering the assessment items one after another. When learners answer an assessment item incorrectly, they see a series of consecutive instructional guidances. These consecutive instructional guidances are designed to help progressively clarify the answer. The instructional guidances are teaching and teaching activities continue until the assessment item is answered correctly. As a result of the literature reviews, it has been determined in studies conducted abroad that similar systems, albeit few, are used in limited numbers. In this research, students were given the right to repeat the same item (by offering progressive instructional guidance each time). Thus, a system design has been designed according to the characteristics of the target audience, with a choice of four options, with only one option left, in other words, three times according to the wrong answer situation. One of the aspects of this research that is different from the studies in the literature is this feature. 


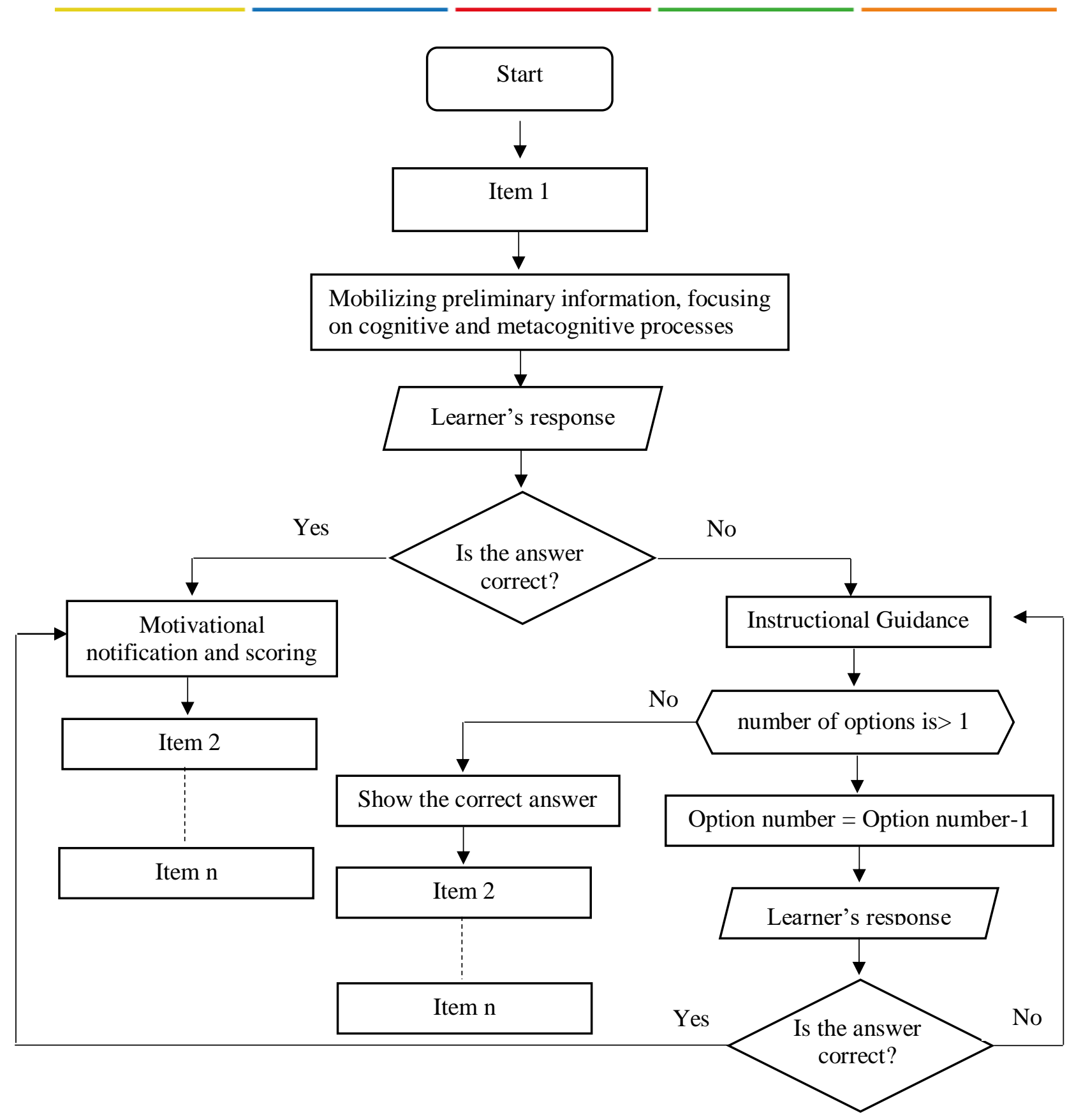

Figure 1. Learner-instructional guidance interaction algorithm

\subsubsection{Stage 2: Creating the prototype (design)}

As a result of the systematic descriptive review of the literature reviews regarding the design of the web-based dynamic assessment system, the studies of the design of the system and the creation of a prototype have been started in order to achieve the objectives of the system to be developed. In this direction, studies on the features of the system to be developed, the creation of contents, the creation of user interfaces and the drafting of assessment tools have been carried out. Angular 5, material design and bootstrap technologies were used on the front of the system, and nodejs, expressjs and mongodb technologies were used as the database on the back of the system.

\subsubsection{Stage 3: Using the prototype (development)}

After the design of the web-based dynamic assessment system, expert opinions were consulted. In this context, the opinions of 3 experts from the field of computer and instructional 
technologies for the development of the environment, 2 experts from the field of mathematics for the course contents and 2 experts from the field of measurement and assessment were consulted. Interviews were conducted with experts to obtain their opinions using a semistructured interview form. System design has been developed in line with the opinions of the field experts regarding the suitability of the design to the dynamic assessment approach, the suitability of the feedbacks developed, the suitability of the interface and visual elements to the target audience, and the suitability of the number of tests and questions. In this context, the appropriateness of the design has been provided by examining the content validity (the content of validity ratio: 1.0). The web-based dynamic assessment system, the prototype of which has been developed and developed in line with expert opinions, has been presented as a pilot application to $475^{\text {th }}$ grade students in a public school in İzmir province under the Ministry of National Education. After the pilot implementation of the web-based dynamic assessment system, a three-dimensional focus group interview was made with $185^{\text {th }}$ grade students' perception of satisfaction and benefit, motivation and engagement, and interface design. During the focus group interview, a semi-structured interview form developed by the researcher was used. The interviews were analyzed by content analysis and the system was evaluated. Themes and frequencies obtained as a result of content analysis are given in Table 5. Following the pilot implementation, studies on the development of the web-based dynamic assessment system continued in line with the feedback received from the students.

\subsubsection{Stage 4: System improvement}

Following the development studies, focus group discussions were held with 12 students prior to the experimental study. In line with the feedback received from the students, efforts to improve the web-based dynamic assessment system continued. As the final product, the system was configured on a server by taking a domain name. System backups were taken periodically.

\subsection{Data Collection Process}

The data collection process of the research started with literature review. As a result of the scanning, 98 articles were examined. Systematic descriptive scanning of the determined articles was made. During the design phase, expert opinion was consulted in structuring the subject contents, revealing the user interfaces and preparing the first drafts of the assessment tools. During the design phase, development focuses were determined in step cycles and these issues were studied. The design focus areas include the interface design of educational web based dynamic assessment system software, user roles and their control design, the design of educational visual elements and the principles of using web based technologies. In design-based research, the improvement process was carried out within the framework of step cycles. The validity and reliability of the subject acquisition items prepared by the experts in the scope of the design of assessment tasks and the creation of the item pool were checked. Cross-checks were provided by three different groups of experts: language expression experts, measurement and assessment experts, and subject matter experts.

As e-learning materials, acquisition-based tests for teaching mathematics subjects of $5^{\text {th }}$ grade students were prepared on the basis of $5^{\text {th }}$ grade mathematics curriculum published by the Ministry of National Education Board of Education and Discipline. Within the scope of the research, "Numbers and Operations" learning area, "Reading and Writing Numbers", "Digit Numbers and Values", "Number and Figure Patterns", "Addition-Subtraction Estimation" and "Addition-Subtraction Process" acquisitions were presented. A total of 15 tests were directed towards five determined acquisitions (there are three multiple choice tests with 10 assessment items in one acquisition). Gamification elements are included to keep students in the system during each acquisition test process and to ensure their continuity in the assessment tasks. 
Students can exit the assessment task at any time. Learners can continue their assessment tasks from where they left off.

\subsection{Data Collection Tools}

Data collection tools used in the research are semi-structured interview form, focus group interview form, achievement test, log recordings and audio and video recordings.

\subsection{Data Analysis}

The data obtained in the research were analyzed using quantitative and qualitative data analysis techniques. Content analysis was used in the analysis of qualitative data. The main purpose in content analysis is to reach the concepts that can clearly describe the data collected and the relationships between these concepts. The most important process in content analysis is to gather similar data together under certain themes and concepts and to illuminate them by organizing them in a way that the reader can understand (Yıldırım \& Şimşek, 2011). The data obtained as a result of the interviews were first transferred to a written environment on a computer and no spelling and punctuation correction was made on any sentence and word. The data obtained was coded and tables specific to each question were created separately and similar or identical themes in the statements of the participants were brought together on a common denominator. Regarding the validity of the content analysis, the data obtained from the interviews were evaluated only by the researcher, and interpreted and cross-checked with another expert from the field. The frequencies of the data are presented through the tables.

The quantitative data obtained in this research include summative assessment pretest scores, summative assessment posttest scores, and student response histories in the web-based dynamic assessment system. In the analysis of quantitative data, descriptive statistics such as percentage, frequency, arithmetic mean were used.

In order to ensure the internal validity of the research, the interview forms and assessment items used within the scope of the research were applied to all learners in the same environment and at the same time and were applied by the researcher. The data obtained from interview forms and assessment items were assessed only by the researcher and interpreted after being examined with another expert from the field. Considering that the research is carried out with the working group, a limited generalization can be made with the results obtained. In this case, the results can only be generalized to groups of students whose educational level corresponds to that of the study group. During the research process, there was no loss of participants that would threaten external validity.

\section{FINDINGS}

In this section, the findings of the research obtained in the order of sub-problems related to the analysis of the data and the assessments related to these findings are presented.

\subsection{Sub-Problem 1: Web-Based Dynamic Assessment System Design Process}

\subsubsection{Findings at the requirement analysis stage}

In order to determine the requirement situation for the development of a web-based assessment system, studies on this subject in the literature have been examined. The studies on the dynamic assessment and static assessment systems developed for e-learning and personalized learning environments in the literature were examined between 2000 and 2019 (Table 3). 
Table 3. Information on Articles Published in the Field Between 2000-2019

\begin{tabular}{lccc}
\hline Source Name & Dynamic Assessment & Formative Assessment & $\begin{array}{c}\text { Web-Based } \\
\text { Assessment }\end{array}$ \\
\hline Science Direct & 257 & 283 & 39 \\
Springer & 211 & 296 & 157 \\
Taylor \& Francis & 52 & 322 & 42 \\
Jstor & 16 & 111 & 17 \\
Eric & 42 & 309 & 15 \\
DergiPark & 14 & 61 & 3 \\
Ulakbim TR Directory Dizin & 5 & 31 & 2 \\
\hline Total & $\mathbf{5 9 7}$ & $\mathbf{1 4 1 3}$ & $\mathbf{2 7 5}$ \\
\hline
\end{tabular}

As it can be seen in Table 3, when the articles published in the literature between 2000 and 2019 are scanned according to keywords, 597 articles with dynamic assessment, 1413 articles with formative assessment, 275 articles with web-based assessment are published. It was found that most of the research were carried out using formative assessment. Within the scope of the research, 98 articles appropriate for the context of the research, the purpose of the research and the problem sentence were selected from among the resources accessed in the literature. It has been determined that $32(32.65 \%)$ of the assessment studies used in the articles assessed were worked with dynamic assessment. 28 of the 32 articles studied with dynamic assessment were published in English and 4 were published in Turkish. 1 of 4 articles published in Turkish is scale development, 2 are literature review and 1 is qualitative descriptive analysis. The sample level distribution used in the articles examined within the scope of the research is given in Figure 2.

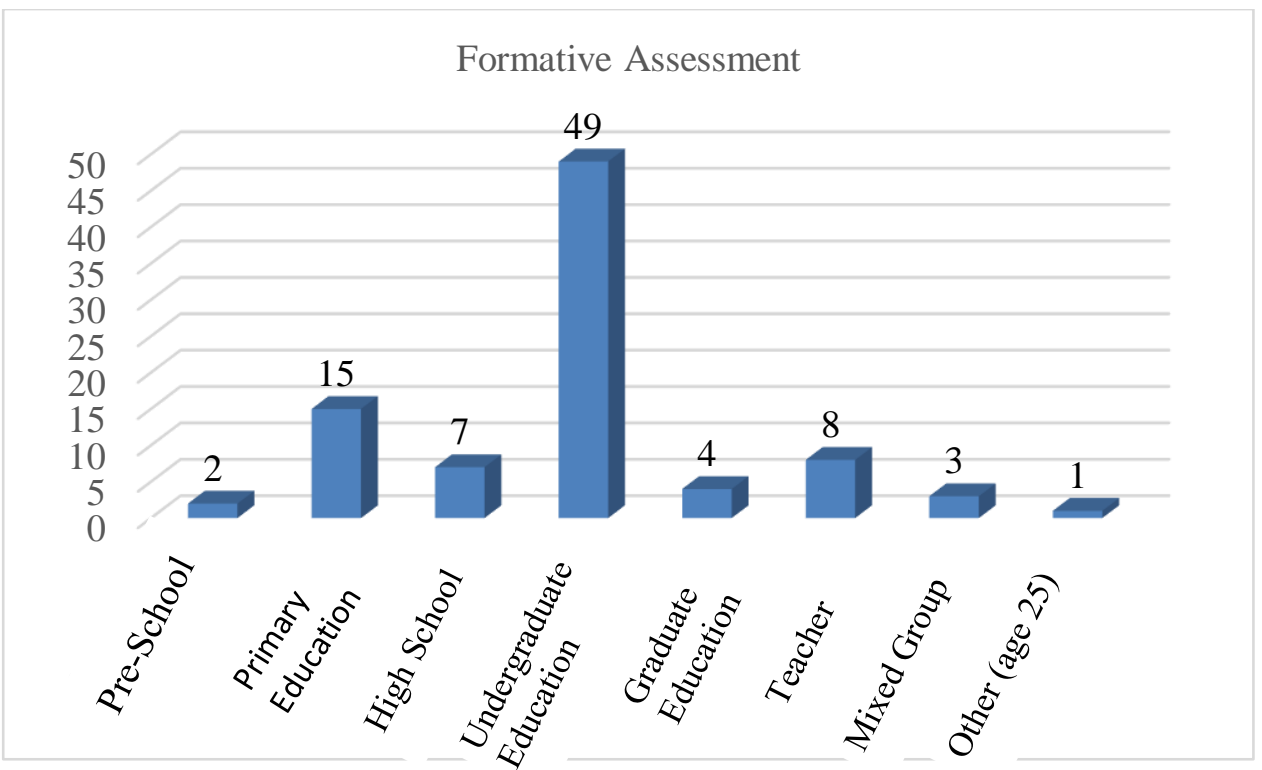

Figure 2. Sampling level distribution used in articles (formative assessment)

As seen in Figure 2, when the sample level distribution used in the articles examined within the scope of the study is examined, it was found that formative assessment was studied mostly at the undergraduate (49 articles, 52\%), at least other (25-age group course, 1 article) and preschool (2 articles) level. The sampling level distribution of the articles studied in dynamic assessment is presented in Figure 3. 


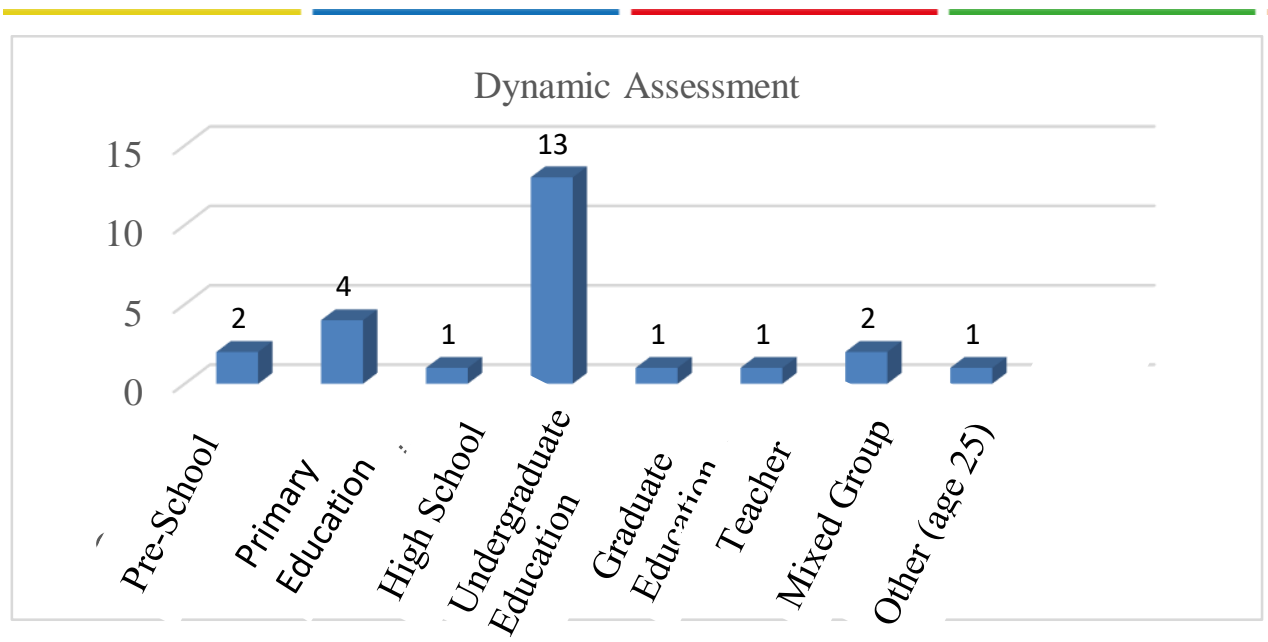

Figure 3. Sampling level distribuıwn used in articles published in the literature (Dynamic assessment)

When the sample level distribution is analyzed in the articles in which dynamic assessment is preferred, it is seen that the highest level is studied with the undergraduate (13 articles) level, at least is high school ( 1 article), graduate ( 1 article), teacher ( 1 article) and other ( 25 years old) ( 1 article) level. It was stated in $25(78.13 \%)$ of 32 articles, in which dynamic assessment study was carried out, that dynamic assessment increased success and was effective. In 7 articles (21.87\%), the variable of success was not examined (review of the literature, scale adaptation study, etc.). It was found that 19 of 25 dynamic assessment articles (76\%) were made with interactionist dynamic assessment, and $6(24 \%)$ were made with interventionist dynamic assessment. In addition, 20 of these articles (80\%) are intended to support in-school learning experiences, and 5 of them (20\%) are intended to support out-of-school learning experiences. Conceptual information was presented in 19 (76\%), conceptual-procedural-strategic information in $5(20 \%)$ and conceptual and procedural information in $1(4 \%)$ for learners.

When studies conducted with dynamic assessment in Turkey are examined, only 4 studies were encountered. On the other hand, it was determined that scale development in 1 article, literature review in 2 articles and qualitative descriptive analysis in 1 article were conducted. However, when the studies conducted in the literature are examined, no study conducted in Turkey based on web-based dynamic assessment has been encountered. However, Kılıç (2004) and Deniz Kan (2007) pointed out the use of portfolios as a dynamic assessment tool in some of their studies. It is determined that many studies have been carried out abroad with the dynamic assessment approach.

When the studies in this direction are examined, there are differences in the designs of these studies. In some studies, there are dynamic assessment elements (such as the option I want to ask my friend, leader board, etc.) while others (for example; assessment task and path. It has been observed that there are differences in algorithms based on scaffolding relationship) are differences in the algorithms used. In this research, it was decided to differentiate the algorithms in assessment task-guiding relations by retaining gamification elements. As a result of the literature review, it has been determined that similar systems, albeit few, are used in a limited number of instructional guidances. In this research, students were given the right to repeat the same item (by offering gradual instructional guidance each time). In this way, a system design has been made according to the characteristics of the target audience, with a choice of four options, with only one option left. In other words, three times according to the wrong answer situation. One of the aspects of this research that is different from the studies in the literature is this feature. In the e-assessment system, which was designed by using similar dynamic assessment systems, points system and gamification elements were included in order to increase learning motivation. The unique aspect of this system on a national basis is that, in addition to 
the limited number of studies abroad, such a system has not yet been configured in our country. The unique aspect of the design in this research, which is international in scale, is that it has a unique quality compared to its peers, with the ability to offer students repeated instruction and instructional guidance in each retry. Another point to be emphasized here is inspired by the trial approach until we find the correct answer, which is a type of feedback. In this context, it was decided to support this research with algorithms based on interventionist dynamic assessment process. Accordingly, the learner-instructional guidance interaction algorithm has been developed (Figure 1).

In the light of the information obtained above, as a result of the study of literature studies, the lack of a study in the context of Vygotsky's sociocultural learning theory (ZPD) and the system design, development and improvement using dynamic assessment in our country, the dynamic assessment can also be used at the target audience level (secondary school level) in our country. In order to design, develop and improve the web baed dynamic assessment system, a unique system should be designed considering the following:

- Supporting students' learning out-of-school in addition to their classroom learning,

- Establishing an environment where students can work outside the class hours regardless of location and time,

- Providing students with an environment where they can work in accordance with their own pace,

- Monitoring and analyzing students' learning process

Based on the learner-instructional guidance interaction algorithm given in Figure 1, considering the characteristics of the target audience through a unique system to be developed as a result of literature reviews and systematic descriptive analysis for the design, development and improvement of the web-based dynamic assessment system, it was decided to go through the stages of determining the system features and creating the prototype.

\subsubsection{Findings at the design (creation of the prototype) stage}

In this section, the design, development and features of the web based dynamic assessment system are explained.

\subsubsection{Web based dynamic assessment system software design process}

Within the scope of the research, it is possible for secondary school students to test themselves with the flexibility of time and space through the internet technologies for learning mathematics lesson topics, to be able to interact with a system that is an instructional approach while testing themselves, to obtain more objective measurements, a quick and instant way towards student performance. A web-based dynamic assessment system has been designed to improve learning and teaching by giving demonstrators, to monitor and analyze assessment results. The architecture of the designed system is given in Figure 4. 


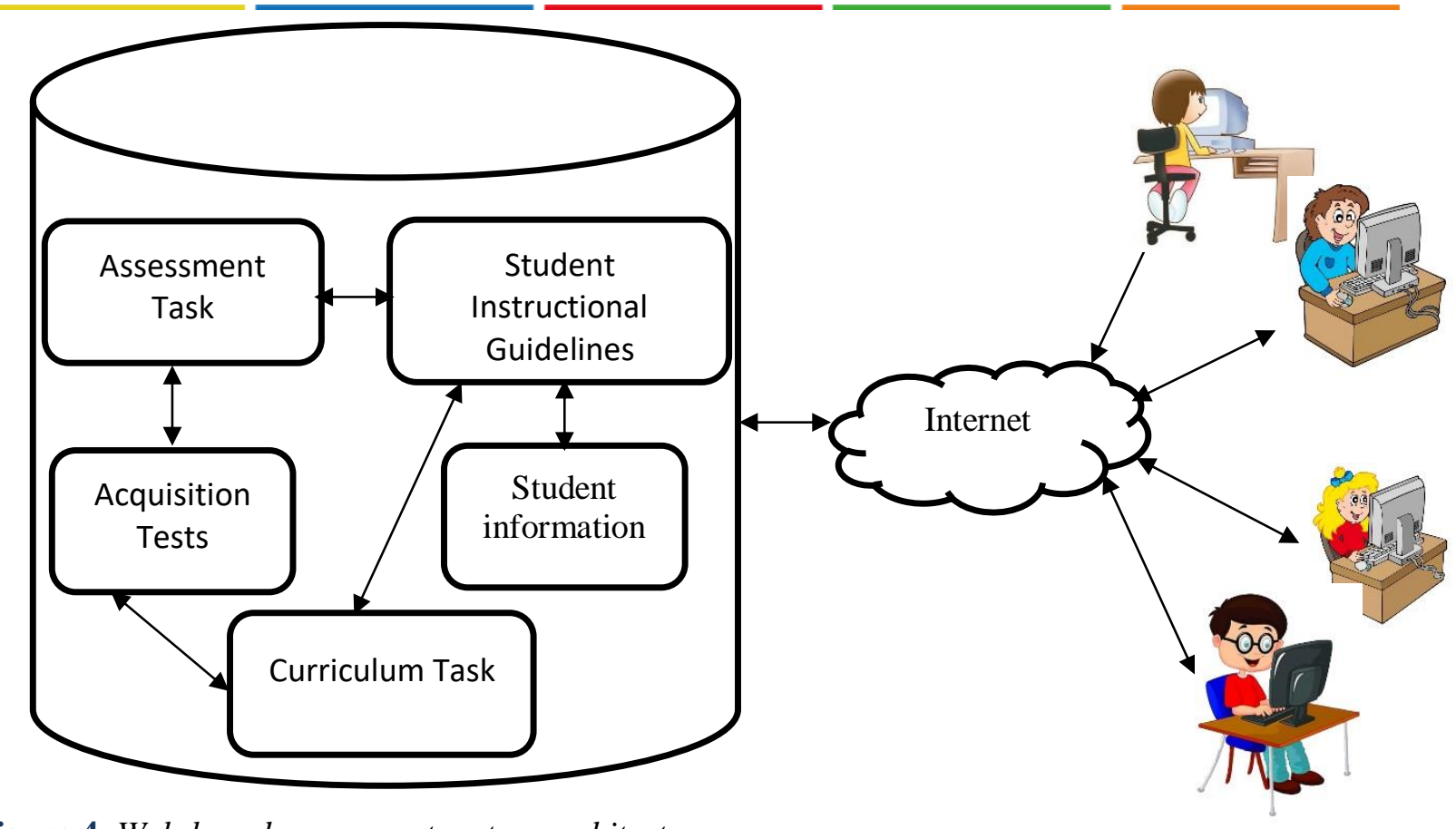

Figure 4. Web-based assessment system architecture

Assessment tasks for the dynamic assessment system were prepared according to the $5^{\text {th }}$ grade mathematics curriculum and added to the acquisition tests in the system. Within the scope of the acquisition tests, 5 acquisition tests were prepared, 3 dynamically designed tests for each acquisition. Students can access the system developed to perform these assessment tasks via the internet and $\log$ in with the user information provided to them or by registering the system. Students who log in to the system can perform the assessment tasks that are managed online and receive instructional guidance on the basis of test, acquisition and item for assessment results. Assessment results are instantly calculated with the functions of the programming languages used in the development of the system and presented to students. Acquisition-based test results are presented to students in detail as instructional guidelines at the end of each test. In addition, instructional guidelines regarding the acquisition and test results are available on each student's profile page.

\subsubsection{Development of web based dynamic assessment system}

When the individual differences are considered, it is important that the feedbacks are individual. However, it is very difficult for educators to determine the deficiencies of the learner and give feedback to the individual (Boud, 2000). Technology-supported environments in terms of feedback should be provided in order for the learners to be able to see his / her current status by testing himself / herself. However, it is noteworthy that there is no common design in creating road maps for assessment systems and feedbacks for web-based formatting in this process where developments continue. In addition, when the distance education studies conducted in Turkey are examined, it is seen that there is not enough focus on e- assessment, and in the studies conducted, the feedbacks are provided to the teacher and the institution rather than the learner. However, there is a need for e-assessment environments where the learner can self-test to observe his own development (Boud, 2000) and make judgments. When the studies carried out using the dynamic assessment method in Turkey are examined, it is found that these studies are quite limited and there is no study conducted with students at secondary school level. Based on this point, a web-based dynamic assessment system has been developed.

Angular 5, material design and bootstrap technologies were used in the development of the web based dynamic assessment system, nodejs, expressjs and mongodb technologies were used as database. The developed systems are configured on a Linux based server that is rented through 
a hosting company. Considering the fact that many students have instant access to the system at the same time, the server is configured to allow 1 terabyte bandwidth for the system to operate uninterruptedly and quickly. After the installation process on the server has been completed, technical tests of the system have been carried out. Following the completion of the tests, the system was made available to students. Within the scope of the research, a simple and easy-touse design was preferred considering the characteristics of the target audience and the system was developed to work on personal computers and tablets.

\subsubsection{Features of the web-based dynamic assessment system}

The web-based dynamic assessment system is a student-centered system, and students can instantly see their achievements for the tests they have taken, examine the assessment tasks, receive instructional guidance that have already been entered into the system, and thus organize their learning instantly. In this system, there are acquisition-based tests prepared for the learning of mathematics lesson subjects of $5^{\text {th }}$ grade students based on primary mathematics curriculum.

Web-based dynamic assessment system can be entered in three different roles: student, teacher and administrator. The administrator can add students (users) to the system, update, delete, add gains suitable for the learning area and sub-learning areas in the curriculum, create, update, delete, create item pool for each acquisition, update, delete. The researcher has assumed the role of manager in the system. The user in the role of teacher can add, update, delete, create item pool for each acquisition, update, delete, and receive detailed reports of each assessment item created by the item pool in accordance with the learning area and sub-learning areas in the curriculum. On the other hand, students can make their own assessments by following the tests they have taken from the list of acquisitions according to the learning area from the profile page, and take dynamic assessment tasks for a new acquisition.

In web-based assessment systems, there are serious problems in keeping the learners in the system and ensuring their continuity, and this results in the learners leaving the system in a short time. In this context, gamification elements are included to keep students in the system in each acquisition test process and to ensure their continuity in the assessment tasks. If the students answer correctly without any guidance (instructional guidance) to the assessment item directed to them, 3 bananas are sent from the box on the tape to the monkey to represent that the item was answered with full score (10 points). Bananas collected in the monkey's basket are instantly reflected in the success score received. If the students respond correctly by taking one instructional guidance to the assessment item, 2 bananas are sent from the box on the tape to the monkey, representing that the item knows correctly ( 8 points) by receiving one instructional guidance. If students respond to the assessment item by taking two instructional guidances, one banana is sent from the box on the tape to the monkey, representing that the item knows correctly (6 points) by receiving two instructional guidances. If students respond to the assessment item with three instructional guidances, no bananas are sent from the box on the tape to the monkey to represent that the item responded by receiving three instructional guidances ( 0 points). With this aspect, it is aimed to ensure the permanence and continuity of the students in the system by embedding gamification elements into the system. A sample assessment item page view is given in Figure 5.

Within the scope of the tests they have taken for the assessment tasks directed to them, three instructional guidances are offered gradually in the system when they encounter difficulties in their learning lives or experience problems in their performance. Instructional guidances are given gradually through an equivalent example without an accurate answer to the assessment item accompanied by a moving robot. If the students respond correctly to the assessment item directed to them, they are supported with expressions to increase their motivation as "Congratulations ... You know.", "Bravo", "Excellent", "Great", etc. before proceeding to the 
next assessment item. After the tests they have taken for the assessment tasks directed to them, the students who took the test through a table stating whether their answers were true or false at the end of the test directed towards them at the end of the test for that achievement and the score that reflects the average score of all students who took that test at that moment it is shown.

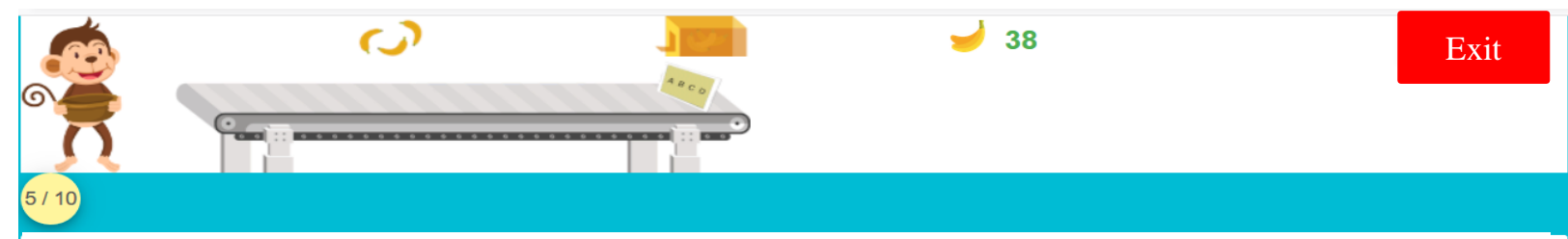

Numbers written according to a certain rule are given as $\mathbf{5 , 1 0 ,} \mathbf{a}, \mathbf{2 0}, \mathbf{b}, \mathbf{3 0}$. What is the result of the $\mathbf{b}-\mathbf{a}$ process?
A $\bigcirc 10$
B $\bigcirc 15$
Congratulations... You know
C $\bigcirc 20$
$\mathrm{D} \bigcirc 25$

Figure 5. Assessment item page view

\subsubsection{Findings during the development (Using the prototype) stage}

The web-based dynamic assessment system, whose prototype was developed, acquisition-based tests were offered to $475^{\text {th }}$ grade students in a public school in İzmir province under the Ministry of National Education as a pilot application. Students were presented with five assessment tasks for acquisition. Within the scope of the research, in order to increase the learning efficiency of the students in accordance with the Rapid Development Model, the achievement developments in the acquisitions determined were examined. The instructional guidance information of students regarding pilot implementation data is presented in Figure 6.

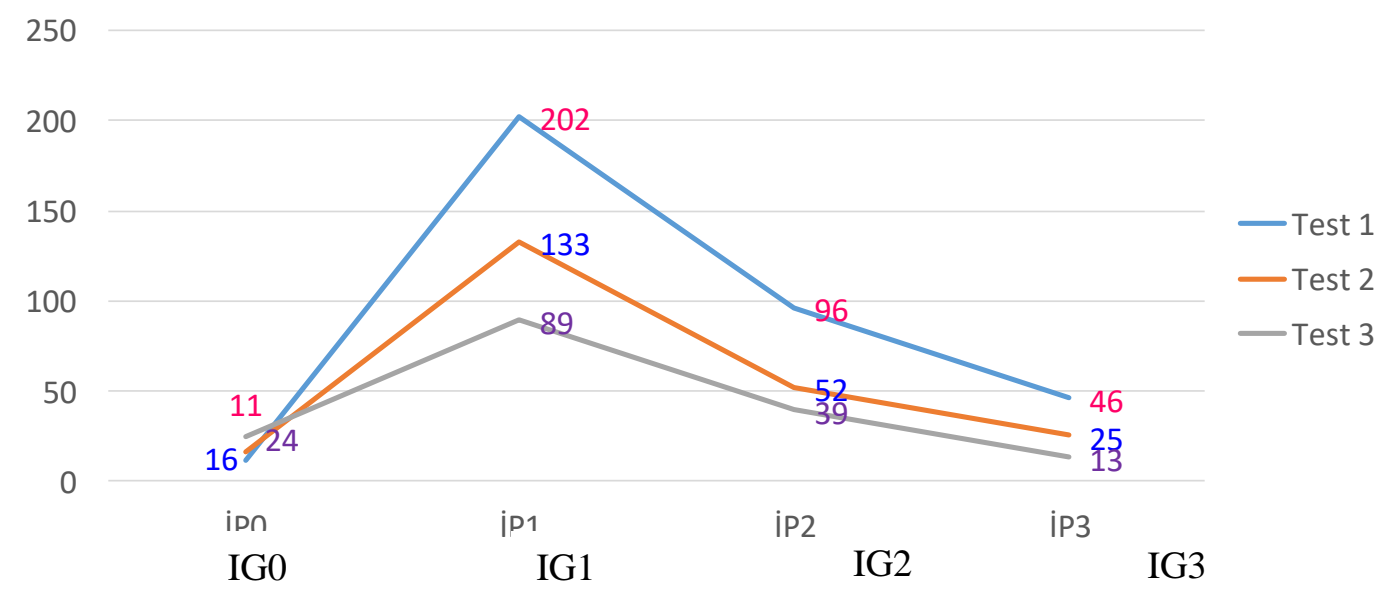

Figure 6. Graph showing the instructional guidance information of students regarding pilot application data

As can be seen in Figure 6, students received 202 instructional guidance 1, 96 instructional guidance 2, 46 instructional guidance 3 within the scope of Test 1, whereas 11 assessment items were answered without receiving instructional guidance. Within the scope of Test 2, 133 instructional guidance 1, 52 instructional guidance 2, 25 instructional guidance 3 received, whereas 16 assessment items were answered without receiving instructional guidance. Within the scope of Test 3, 89 instructional guidance 1, 39 instructional guidance 2, 13 instructional 
guidance 3 received, whereas 24 assessment items were answered without instructional guidance. In each test, it was determined that the students needed more instructional guidance in the first items of the test (they needed more for instructional help), and these needs (instructional help needs) gradually decreased in the following items of the test. Achievement points taken on the basis of gain in pilot implementation are presented in Table 4.

Table 4. Pilot Application Achievement Based Success Points Chart

\begin{tabular}{cccccc} 
Acquisition & $\begin{array}{c}\text { Number } \\
\text { Name } \\
\text { Vigits and } \\
\text { Values }\end{array}$ & $\begin{array}{c}\text { Reading } \\
\text { and } \\
\text { Writing } \\
\text { Numbers }\end{array}$ & $\begin{array}{c}\text { Number } \\
\text { and Shape } \\
\text { Patterns }\end{array}$ & $\begin{array}{c}\text { Addition and } \\
\text { Subtraction } \\
\text { Estimation }\end{array}$ & $\begin{array}{c}\text { Addition and } \\
\text { Subtraction } \\
\text { Process }\end{array}$ \\
\hline Test1 & 84.32 & 90.73 & 80.22 & 74.00 & 79.33 \\
Test2 & 91.87 & 92.12 & 85.60 & 86.00 & 86.50 \\
Test3 & 94.40 & 93.09 & 89.60 & 92.00 & 92.00 \\
\hline
\end{tabular}

It was found that the students' success scores constantly increase in each acquisition, the instructional guidance they receive in each test decreases constantly and they can perform the next assessment tasks without help. Based on the data here, students can see their success levels for the tests they have taken through the dynamic assessment system, they can instantly examine their assessment tasks and performances, they can arrange their learning instantly by taking the instructional guidances entered into the system, and thus, as Vygotsky expresses that the students can do without help. It can be stated that it is possible to fill the gap between what they can do with help, with dynamic assessments and support Vygotsky's sociocultural learning theory.

After the pilot implementation of the web-based dynamic assessment system, a threedimensional focus group interview was made with the students' perception of satisfaction and benefit, motivation and engagement, and interface design. During the focus group interview, a semi-structured interview form developed by the researcher was used. The interviews were analyzed by content analysis and the system was evaluated. Themes and frequencies obtained as a result of content analysis are given in Table 5.

Table 5. Content Analysis Themes and Frequencies

\begin{tabular}{lc}
\hline Theme & Frequency (f) \\
\hline Feeding the monkey & 18 \\
Competition score & 16 \\
Contribution of learning to mathematics & 14 \\
Ease of learning the system & 12 \\
The system is guiding & 11 \\
Visual elements & 11 \\
Legibility of the articles & 11 \\
Access to acquisitions and tests & 10 \\
Using hints & 7 \\
\hline
\end{tabular}

As can be seen in Table 5, as a result of the content analysis conducted as a result of focus group interviews, 9 themes were obtained. As a result of focus group meetings;

"How did the system guide you in unfamiliar questions?" Students' answers to the question posed as; 
K1: "It leads us to the correct solution of the questions and gives clues. I think we would not be able to solve the next questions more easily without clues."

K6: "When we get the question wrong, we can see that we did it wrong. We can continue to answer the question correctly."

While solving the questions in the questions that the students did not know, it was found that they were directed to the correct solution of the questions thanks to the instructional instructions given by the system, they found the correct answers more easily, and they used these instructional guidances in similar questions.

"Was the visual robot cute?" Students' answers to the question posed as;

K4: "Yes, I think it is cute and it is fine."

K6: "I think it was good, the robot was swinging left and right, moving where it was."

It has been found that the visual elements (monkey, robot) in the system are interesting, cute and very beautiful, they help students, can be bigger, entertain themselves when they are tired or bored.

"Whether to feed the monkey or not?" Students' answers to the question posed as;

$\mathrm{K} 1$ : "I think it is fun."

K7: "I think the monkey is beautiful, looking at it feels fun."

It was found that there was a monkey feeding status associated with student responses given to the assessment items in the system, that they motivated them positively and that they tried to feed the monkey by answering the assessment items more correctly.

"In your opinion, having a competition score; Whether or not? How did it affect you?" Students' answers to the question posed as;

K4: "I think so. We can understand how we can improve ourselves better."

K7: "I think so too. But it may be that he does greed, not to determine our level."

It was found that they should have a competition score in the system, they can understand how they can improve themselves better, they can follow their levels, they will solve less tests in the absence of a success score, and that they motivate them positively, they try to get more points. "Would the learning here contribute to the Mathematics course?" Students' answers to the question posed as;

K3: "Yes, it will help."

K8: "Yes it does. Because he explains it as our teacher explains and looks like the questions he solves."

It was found that learning in the system could contribute to mathematics lesson.

$\mathrm{K} 2$ "The robot is big, the sample picture in the tips is small. It would be better if the robot got a little smaller and the picture was enlarged." made a statement.

$\mathrm{K} 13$ "When we solve the question, pressing the answer button repeatedly, the situation of giving points constantly needs to be corrected." made a statement.

When marking the answer of the question in the system, a software error has been detected stating that it can exceed 100 points by clicking the answer button without waiting for the other problem to appear.

$\mathrm{K} 7$ "The bravo statements, whose questions come to consciousness, were much more effective." and

K9 "The feedbacks were super, as I know, expressions like bravo and well done motivate me even more, I like it very much." made a statement. 
"Bravo, Perfect, Congratulations ... You know, etc." it was found that motivational expressions given in the system are much more effective.

$\mathrm{K} 12$ "At the end of the test, you got the following score and you passed so many people, it is good for us to see our own development, but it is not realistic to always give it as "you have passed 25 people who have taken this test", it should be corrected." declared.

At the end of the acquisition-based test, it was determined that giving the following score and giving the motivational message that you have passed so many people is beneficial in terms of seeing student developments.

$\mathrm{K} 3$ "I like everything. The system was beautiful, you can easily move forward. Get in other lessons. It is nice to be in the computer environment, easier." and

K6 "... I was able to learn easily, it did not have a very difficult interface." made a statement.

It has been found that when students use the system, they do not have to get help from someone else, but they have questions to take action, they may be good if they have a paper pencil, they can learn the system easily, they do not have a very difficult interface, they are not a difficult system, they can easily access, they can find the acquisitions related to the lesson and assessment they can easily reach their duties. It has been found that there is no difficulty in reading the articles in the system, but where the instruction is given, the articles are very intertwined and the numbers in the tables with sample solutions are not read.

According to the findings obtained from interviews with students using the system, it is possible to conclude that the web-based dynamic assessment system is useful and that information about their interactions in such systems is presented to them with graphic and visual elements positively affecting their learning processes.

\subsubsection{Findings at the Stage of Design Changes Based on Assessment}

Following the pilot implementation, studies on the development of the web-based dynamic assessment system continued in line with the feedback received from the students. In this context, as a result of focus group discussions with students;

- The problem that the system constantly scores (assessment of a software bug in the system) has been fixed as a result of clicking on the answer of an assessment item repeatedly before another assessment item is displayed in the assessment tasks that students take for the acquisition.

- It was stated that the visual robot could be bigger and the subject contents could also be included. In this regard, the robot has been developed a little more. Instructional guidance on the subject content of the achievements was decided to be given in more detail and on the example in the context of the subject scope and the system was developed in this context.

- The students stated that the sample pictures in the hints presented in the context of instructional guidance in the assessment item are small. In this regard, improvements have been made in the system.

- Expressions presented as motivation element have been further developed.

- Some students stated that they did not have difficulty in reading the articles on the pages, but the interfaces where instructional guidances were given were very intertwined and the numbers in the tables were not read. Improvements were made in these interfaces and made more readable.

In this context, the necessary improvements in the web-based dynamic assessment system were made with expert guidance. The final product for the system is configured on a server by purchasing a domain name. System's backups were taken periodically. 


\subsection{Sub-Problem 2: Findings Related to the Second Research Problem (Improvement Stage)}

In this section, the opinions of the students using the web-based dynamic assessment system are given. In the 2018-2019 academic year, focus group interviews were conducted with 12 students using this system in two public secondary schools in Ankara. During the interviews, a semi-structured interview form developed by the researcher was used. Interviews were analyzed with content analysis and the system was evaluated. Themes and frequencies resulting from content analysis are given in Table 6.

Table 6. Content Analysis Themes and Frequencies

\begin{tabular}{lc}
\hline Theme & Frequency (f) \\
\hline Instructional guidances & 12 \\
The effectiveness of the system & 12 \\
Visual elements & 12 \\
Competition score & 12 \\
Ease of learning the system & 12 \\
Access to acquisitions and tests & 12 \\
Monkey feeding anxiety & 11 \\
Individual and group graphics & 10 \\
Legibility of the articles & 10 \\
System sending notification & 9 \\
\hline
\end{tabular}

As a result of focus group discussions with students;

"How did the hints presented in the system guide you in questions you do not know?" The question posed as,

K9: "I really liked how it helped with questions we couldn't do. It shows our score. I really liked such a test."

K12: "Once I got the clues from the questions, I was able to do other questions in similar questions."

It has been found that the students are directed to the correct solution by solving the questions in questions they do not know, they may not be able to solve the following questions more easily without instructional guidance, and instructional guidance for the solution is very helpful.

"When you evaluate your acquisition-based learning, what are your thoughts on whether the system is effective in your success development?" The question posed as, K4: "I really liked how he helped with questions we couldn't do. It shows our score. I liked such a test very much. My success score has increased continuously."

K7: "I like everything. The system was nice, I enter from home. Get in other lessons. It is better to have a computer environment, we do not have difficulty. It helps us be more successful in lessons."

It has been found that students can observe their progress in learning acquisition-based mathematics, the system is very successful and they want to use this system in other courses.

"Were the visuals (monkey, hint robot, banana) in the system interesting and cute?" The question posed as,

K5: "While it is difficult on the one hand, something is burning like a game, like a monkey. The robot helps us understand where we made mistakes. These were the things I liked the most. I think this system is very nice instead of paper and pencil." 
K3: "I like monkeys. It was nice to say how many people I passed."

It has been determined that the visual elements of monkey, robot and banana in the system are interesting, fun and beautiful, and can entertain students when they are tired or bored.

"What are your thoughts about having a competition score in the system? Whether or not points?" The question posed as,

K1: "I can see how many people I have passed as points. There must be points."

K8: "I think it is better to have a competition score, we try to pass, we feel an ambition."

It was found that there should be a competition score in the system, students can follow their development level in their learning lives, that there is a competition score motivates their students positively and they make ambition.

"What are your thoughts on the individual and group graphics in the system?" The question posed as,

K1: "Thanks to the graphics, I can see my past. I can also see our situation within the group. It was very understandable and beautiful."

K8: "With the graphics found at the end of the test, I can see both my own situation and the averages of others who took this test, I can see in which questions I got hints, how many hints I got, I can assess myself. It was pretty good."

It was found that individual and group graphics in the system can see student developments by comparing them with group developments, and that the instructional guiding usage status charts given at the end of each test are understandable and useful and that they can follow their own levels.

"Did feeding the monkey cause anxiety?" The question posed as,

K4: "Feeding the monkey did not cause any anxiety, I have to answer the questions more carefully and feed the monkey. It was more fun."

K6: "I don't have much trouble about this. Feeding the monkey is not a problem, it's fun."

It was determined that feeding monkeys did not cause any anxiety in students and this situation led students to solve questions more carefully.

"How helpful was the system in notifying you?" The question posed as,

$\mathrm{K} 2$ : "It is very helpful for the system to provide feedback when we do it wrong."

K9: "The feedback has been super, as I know, phrases like bravo and well done motivate me even more, I like it very much."

It has been found that it is motivating that the system gives feedback to the students while answering the questions and the notifications are useful.

"Did you have in difficulty reading the articles?" The question posed as,

K3: "Normally I did not have any difficulties."

K5: "Normally legible, questions, tips, graphics can be read properly."

It was found that students did not have any difficulties while reading the writings in the system and that the articles were legible.

According to the findings obtained from the interviews with students using the system, it is possible to conclude that the web-based dynamic assessment system is effective and useful, and that information about student interactions in the developed system with graphic and visual elements positively affects the learning processes. 


\section{DISCUSSION and CONCLUSION}

Bloom (1984) stated that one-to-one tutorial support increases students' achievements by two standard deviations. In this context, the field where many technology supported environment designs are developed in order to support students from past to present and to ensure their development is seen in the literature (Ashton, et al. 2006; Costa, Kothe, Mullan \& Butow, 2010; Critchley, Ware, Kumta \& Wong, 2009; Marinagi, 2011; Wang, 2007, 2010, 2011,2014; Wang, Wang, Wang \& Huang, 2006; Zou \& Zhang, 2013). At the same time, this point of view is closely related to Vygotsky's sociocultural learning theory and "The Zone of Proximal Development". The convergent development area is expressed as the gap between what the student can do without help and what he can do with help (Bodrova \& Leong, 1996; Vygotsky, 1978). It can be said that one of the alternatives to fill this gap is dynamic assessment. Because one of the main objectives of dynamic assessment is to improve the performance of learners by providing instructional aids with assessment tasks. In this context, the feature that distinguishes dynamic assessment from static assessment can be explained by feedback concept. In dynamic assessment, feedbacks are based on performance in an assessment task; rather than cognitive, affective and motivational information about students' performance, it is done with scaffolding to guide students to the correct answer. While dynamic assessments have been used extensively in foreign language teaching in classroom practices until today, they have started to be transferred to other fields thanks to the developing teaching technologies. One of the benefits of instructional technologies is that with the help of web-based systems, learners can monitor their development by testing themselves repeatedly, they can see their strengths and deficiencies with meaningful guides, and they can improve their learning performance by improving their learning strategies.

As Bloom (1984) stated that, the way to increase students' achievements with one-to-one tutorial support can be the subject of education technologies today. When the studies in this direction are examined in the literature, there are differences in the designs of these studies. In some studies, there are dynamic assessment elements (such as the option I want to ask my friend, leader board, etc.) while others (for example; assessment task and path. It has been observed that there are differences in algorithms based on scaffolding relationship) are differences in the algorithms used. In this research, it was decided to differentiate the algorithms in assessment task-guiding relations by retaining gamification elements. Accordingly, the learner-instructional guidance interaction algorithm has been developed (Figure 1). Instructional support is a concept related to the help given in case of a problem. As the working principle of the designed system; it is possible to give students (without moving to a new assessment task) consecutively the possible guiding (scaffolding) of the current assessment task in the context of a certain strategy. The design in this research has been associated with a special type of feedback, "continue to answer the assessment item until you find the correct answer" approach, and the design of the existing research is based on this.

In this research, a web-based environment that combines the principles of dynamic assessment and gamification with a dynamic assessment algorithm developed within the scope of the research has been developed. In the research, firstly, the requirement analysis for the web-based dynamic assessment system was done by examining the studies conducted in this context in the literature. Within the scope of the research, systematic descriptive scanning was carried out by selecting 98 articles suitable for the context, purpose and problem sentence among the resources accessed in the literature. It has been determined that $32(32.65 \%)$ of the studies used in the articles evaluated were worked with dynamic assessment. When the sample level distribution was examined in the articles in which dynamic assessment was preferred, it was seen that the highest level of study was at the level of undergraduate (13 articles), at least high school (1 article) and graduate (1 article). In 25 (78.13\%) of these articles, it was found that dynamic 
assessment further increased success and was effective. It was found that in 19 (76\%) of the articles in which the success variable was examined, interactionist dynamic assessment was performed in $6(24 \%)$ and interventionist dynamic assessment. When the studies conducted with dynamic assessment in our country are examined, the findings are quite limited (only 4 studies are available; 1 study is scale development, 2 studies are literature review and 1 study is a qualitative descriptive analysis study). In this research, no studies conducted in Turkey based on web-based dynamic assessment were encountered. The necessity of an e-assessment system, which has the feature of supporting the out-of-school learning experiences in addition to the in-school learning experiences of the students at the target audience level (secondary school level), which includes different instructional guidances according to different types of information, has been revealed. In this context, it has been found that the design, development and improvement of the web-based dynamic assessment system is needed.

As a result of the literature review, it has been determined that similar systems, albeit few, are used in a limited number of instructional guidances. In this research, students were given the right to repeat the same item (by offering gradual instructional guidance each time). In this way, a system design has been made according to the characteristics of the target audience, with a choice of four options, with only one option left, in other words, three times according to the wrong answer situation. One of the aspects of this research that is different from the studies in the literature is this feature. In the e-assessment system, which was designed by using similar dynamic assessment systems, points system and gamification elements were included in order to increase learning motivation. The unique aspect of this system on a national basis is that, in addition to the limited number of studies abroad, such a system has not yet been configured in our country. The unique aspect of the design in this research, which is international in scale, is that it has a unique quality compared to its peers, with the ability to offer students repeated instruction and instructional guidance in each retry. Another point to be emphasized here is inspired by the trial approach until we find the correct answer, which is a type of feedback. In this context, it was decided to support this research with algorithms based on interventionist dynamic assessment process. Accordingly, the learner-instructional guidance interaction algorithm has been developed (Figure 1).

The web-based dynamic assessment system adopted in this research was designed as a cakeform interventionist dynamic assessment. As a result of the literature reviews, a design was realized in line with the design principles determined by making use of the findings obtained from the dynamic assessment studies. The first prototype of the system was created with reference to the rapid prototyping model. System design has been developed in accordance with the opinions of the field experts regarding the suitability of the design to the dynamic assessment approach, the suitability of the feedbacks developed, the suitability of the interface and visual elements to the target audience, and the suitability of the number of tests and questions. In this context, the appropriateness of the design was provided by examining in the context of content validity. During the development of the system, a pilot application was made to $475^{\text {th }}$ grade students in İzmir. Focus group meetings were held with $185^{\text {th }}$ grade students determined after the pilot implementation. As a result of the pilot implementation and focus group discussions with students, efforts to improve the system continued. During the improvement phase, a web-based dynamic assessment system was opened for $125^{\text {th }}$ grade students in Ankara. After the use of the system, semi-structured focus group interviews were held with the students. In the focus group interviews, the students are directed to the right solution while solving the questions that they do not know, the instructional guidance for the solution is very helpful, the students can observe the development of their achievements, the system is very successful, the other elements that they want to use this system in other courses, the visual elements (monkey, robot and banana) is interesting, fun and beautiful, it can entertain students when they are tired or bored, it is motivating that the system gives scaffolding to the 
students while solving the questions, and the notifications are useful, the students can learn the system easily and the system is guiding. Thus, as stated by Vygotsky, it is possible to fill the gap between what students can do without help and what they can do with help, and that supports Vygotsky's sociocultural learning theory.

Through the web-based dynamic assessment system developed in this research, students at the secondary school level can instantly see their achievements for the tests they have taken, instantly review the assessment questions and their answers, and can take pre-entered guides into the system and thus organize their learning instantly. In addition, it was tried to contribute to the students' educational goals by determining whether the student had an effective learning experience, questions that he / she answered incorrectly as a result of carelessness, and whether the course contents were deficient. In addition, with this study, it can be contributed to its extensive use in education and training in the context of the development of assessment environments in the context of advanced applications of computer-aided web-based education and training through internet technologies.

As part of the limitations of the research, there have been situations where the use of voice recorders for the recording of voice recordings by the parents of students in focus group interviews with students has occurred. In these cases, interview notes were kept by the researcher in order to determine the results of the research correctly and to realize their analysis realistically. For the effectiveness of the developed system, interaction situations, achievement developments, instructional orientation status of the students were studied within the scope of the acquisitions for $5^{\text {th }}$ grade mathematics course. The interaction situations of students with regard to the effectiveness of the developed system, their success development, instructional guidance status and the probability of transition between situations can be revealed with an experimental study. The instructional guidance offered in this system is not limited to $5^{\text {th }}$ grade mathematics lessons, but it is more holistic and covers videos, animations, lectures, etc. content designs can also be developed and presented to students. In addition, students' interactions in the system can be presented to students through learning panels using "Lag sequential analysis", "markov chains", etc. methods. In this context, it is assessed that students' sequential navigation will provide an important finding in estimating past, present and future patterns.

\section{Declaration of Conflicting Interests and Ethics}

The authors declare no conflict of interest. This research study complies with research publishing ethics. The scientific and legal responsibility for manuscripts published in IJATE belongs to the author(s).

\section{ORCID}

Arif TULUK (D) https://orcid.org/0000-0003-3130-6005

Halil YURDUGÜL (D) https://orcid.org/0000-0001-7856-4664

\section{REFERENCES}

Allal, L., \& Ducrey, G. P. (2000). Assessment of- or in- the zone of proximal development. Learning and Instruction, 10, 137-152.

Ashton, H.S., Beevers, C.E., Korabinski, A.A., \& Youngson, M.A. (2006). Incorporating partial credit in computer-aided assessment of Mathematics in secondary education. British Journal of Educational Technology, 37(1), 93-119. https://doi.org/10.1111/j.1467-8535. 2005.00512.x

Bloom, B.S. (1984). The 2 sigma problem: The search for methods of group instruction as effective as one-to-one tutoring. Educational Researcher, 13(6), 4-16.

Bodrova, E., \& Leong, D. J. (1996). Tools of the mind: The Vygotskian approach to early childhood education. Englewood Cliffs, NJ: Merrill/Prentice Hall. 
Boud, D. (2000). Sustainable assessment: rethinking assessment for the learning society. Studies in continuing education, 22(2), 151-167. Erişim adresi: http://dx.doi.org/10.108 $\underline{0 / 713695728}$

Bransford, J. C., Delclos, J. R., Vye, N. J., Burns, M., \& Hasselbring, T. S. (1987). State of the art and future directions. In C. S. Lidz (Ed.), Dynamic assessment: An interactional approach to evaluating learning potential (pp. 479-496). New York: Guilford Press.

Campione, J.C., \& Brown, A.L. (1985). Dynamic assessment: One approach and some initial data. Technical report no. 361, Univ. of Illinois at Urbana-Champaign, Champaign, IL. (ERIC ED269735).

Campione, J. C., \& Brown, A. L. (1987). Linking dynamic assessment with school achievement. In C. S. Lidz (Ed.), Dynamic assessment: An international approach to evaluating learning potential (pp. 82-115). New York: The Guilford Press.

Critchley, L. A., Kumta, S. M., Ware, J., \& Wong, J. W. (2009). Web-based formative assessment case studies: role in a final year medicine two-week anaesthesia course. Anaesthesia and Intensive Care, 37(4), 637-645.

Costa, D. S., Mullan, B. A., Kothe, E. J., \& Butow, P. (2010). A web-based formative assessment tool for Masters Students: A pilot study. Computers \& Education, 54(4), $1248-1253$.

Deniz Kan, Ü. (2007). Okul öncesi eğitimde değerlendirme aracı olarak portfolyo. Gazi Üniversitesi Gazi Eğitim Fakültesi Dergisi, 27(1), 169-178.

Elliott, J. G. (2003). Dynamic assessment in educational settings: Realizing potential. Educational Review, 55, 15-32.

Haywood, H. C., Brown, A. L., \& Wingenfeld, S. (1990). Dynamic approaches to psychoeducational assessment. School Psychology Review, 19, 411-422.

Haywood, H. C., \& Lidz, C. S. (2007). Dynamic assessment in practice. Clinical \& educational applications. New York: Cambridge University Press.

Kılıç, G. B. (2001). Oluşturmacı fen öğretimi. Kuram ve Uygulamada Ĕgitim Bilimleri Dergisi, $1,7-22$.

Marinagi, C. (2011). Web-based adaptive self-assessment in Higher Education. Education in a technological world: communicating current and emerging research and technological efforts, 978-84.

Mayer, R. E. (1992). Thinking, problem solving, cognition. New York, NY: W.H. Freeman and Company.

Moore-Brown, B., Huerta, M., Uranga-Hernandez, Y., \& Peña, E. D. (2006). Using dynamic assessment to evaluate children with suspected learning disabilities. Intervention in School and Clinic, 41, 209-217.

Richey, R. C., Klein, J. D., \& Nelson, W. A. (2004). Developmental research: Studies of instructional design and development. Handbook of research for educational communications and technology, 2, 1099-1130.

Sternberg, R. J., \& Grigorenko, E. L. (2001). All testing is dynamic testing. Issues in Education, 7, 137-170.

Van den Akker, J. (1999). Principles and methods of development research. In Design approaches and tools in education and training (pp. 1-14). Springer Netherlands.

Vygotsky, L. S. (1978). Mind in society: The development of higher psychological processes. Cambridge, MA: Harvard University Press.

Wang, K. H., Wang, T. H., Wang, W. L., \& Huang, S. C. (2006). Learning styles and formative assessment strategy: enhancing student achievement in Web-based learning. Journal of Computer Assisted Learning, 22(3), 207-217.

Wang, T. H. (2007). What strategies are effective for formative assessment in an e-Learning environment? Journal of Computer Assisted Learning, 23, 171-186. 
Wang, T. H. (2008). Web-based quiz-game-like formative assessment: Development and evaluation. Computers \& Education, 51, 1247-1263.

Wang, T. H. (2010). Web-based dynamic assessment: Taking assessment as teaching and learning strategy for improving students' e-Learning effectiveness. Computers \& Education, 54(4), 1157-1166.

Wang, T. H. (2011). Implementation of web-based dynamic assessment in facilitating junior high school students to learn mathematics. Computers \& Education, 56, 1062-1071.

Wang, T. H. (2014). Developing an assessment-centered e-Learning system for improving student learning effectiveness. Computers \& Education, 73, 189-203.

Yıldırım, A. \& Şimşek, H. (2011). Sosyal bilimlerde nitel araştırma yöntemleri. 8. Basım, Ankara: Seçkin Yayınları.

Zou, X. \& Zhang, X. (2013). Effect of different score reports of Web-based formative test on students' self-regulated learning. Computers \& Education, 66, 54-63. 